\title{
Systematic early obstetrical assistance at calving: II. Effects on dairy heifer calf growth, health, and survival to weaning
}

\author{
M. Villettaz Robichaud, ${ }^{* 1}$ D. L. Pearl, ${ }^{*}$ S. M. Godden,† J. Rushen,ł S. J. LeBlanc, ${ }^{*}$ and D. B. Haley ${ }^{* 1}$ \\ *Department of Population Medicine, Ontario Veterinary College, University of Guelph, Guelph, ON, N1G 2W1, Canada \\ †Department of Veterinary Population Medicine, University of Minnesota, St. Paul 55108 \\ łUniversity of British Columbia, Dairy Educational and Research Center, Agassiz, BC, V6T 1Z4, Canada
}

\section{ABSTRACT}

Good calving management should not only ease the transition of cows into lactation, but also contribute to providing healthy replacement animals for the herd. Difficulty during parturition has been found to be detrimental to the offspring. Because of the association of obstetrical intervention with undesirable outcomes, the general management recommendation for calving is to let cows give birth unassisted whenever possible. Unfortunately, very few studies have investigated the effects of planned early assistance during calving, regardless of whether or not another problem exists. To investigate the effects of early assistance during apparently normal calvings, a clinical trial was conducted on 257 Holstein cows. They were observed through the second stage of calving, and before calving they were divided randomly between 2 assigned interventions: not assisted or early assistance during the second stage of parturition. After calving, the animals were classified into 4 actual calving intervention groups: too quick to be assisted, not assisted, early assistance, and late assistance (for cows in the not assisted group that did not calve unassisted within the $1 \mathrm{~h}$ maximum time allowed). Early assistance was given 15 min after first sight of both front hooves of the calf and done using human force only. Heifer calves $(\mathrm{n}=129)$ born from enrolled dams were followed until weaning to assess the effect of assigned and actual calving interventions on their growth, health, and survival. Heifer calves' weight at birth was positively associated with weight at $7 \mathrm{wk}$, but the effect varied by assigned and actual intervention. As a routine management practice, giving early assistance during calving to dairy cows did not influence average daily gain, health, or survival in dairy heifer calves up to weaning at $7 \mathrm{wk}$ of age.

\footnotetext{
Received March 24, 2016.

Accepted September 17, 2016.

${ }^{1}$ Corresponding authors: marianne.villettaz@gmail.com and dhaley@uoguelph.ca
}

Key words: calving assistance, obstetrics, calf survival, growth

\section{INTRODUCTION}

The aim of calving management is to help the dairy cow begin lactation in good health, and to produce good-quality replacement heifers. Recent literature reports that heifer calves' very early experience in life can affect them even as mature animals. Heinrichs and Heinrichs (2011) found that heifers born from a difficult birth had significantly lower milk production in their first lactation. In the United States, the risk of dystocia in dairy animals has been estimated to be $13.7 \%$ (Mee, 2008a). The published literature uses different definitions of dystocia, calving difficulty, calving ease, and level of calving assistance to assess the effects of calving on dairy calves at the time of birth and later in development. Unfortunately, there is currently no consensus on a standard scoring system for calving assistance that would permit clear comparisons among studies (Mee, 2008a). Furthermore, very few published studies provide detailed information on the specific criteria or reasons for assistance or on the timing of the assistance provided in relation to the stage of parturition. The general recommendation in the industry is to let cows calve unassisted when dystocia or malpresentation are absent (Mee, 2008b).

Over the last decade, some studies have investigated the effects of mild and severe calving difficulty on heifer calves. Difficult calvings have been negatively associated with calf health, growth, and survival. Barrier et al. (2012) studied the association between moderate- and high-difficulty calvings and dairy heifer calves' growth to weaning; similar to Bellows et al. (1988), they found no significant difference compared to unassisted calvings. The odds of respiratory and digestive problems between birth and $120 \mathrm{~d}$ of age have been found to be greater in heifer calves born from calvings with mild and severe dystocia compared with unassisted calvings (Lombard et al., 2007). The same study concluded that 
overall, heifer calves born from a calving with severe dystocia had higher odds of dying before $120 \mathrm{~d}$ of age than calves born from unassisted calvings (Lombard et al., 2007). Barrier et al. (2012) found that heifer calves born from moderate- and high-difficulty calvings had a greater hazard of dying before weaning than heifers born from unassisted calvings. The outcomes might have been worse had obstetrical assistance not been provided, but there is still a lack of evidence on which to base criteria and means of intervention. It has been suggested that assistance during calving should be provided within $65 \mathrm{~min}$ after the appearance of the feet of the fetus to achieve the highest probability of calf-cow survival (Schuenemann et al., 2011).

A survey conducted on 236 Canadian dairy farms found that $27 \%$ of dairy producers systematically assisted all of their animals at calving, without regard for the necessity of intervention or the likelihood of calving difficulty (Villettaz Robichaud et al., 2016). However, unlike the effects of calving difficulty, very little research has been published concerning the effects of early systematic assistance on the growth and health of calves. Bellows et al. (1988) found that systematic early obstetrical assistance in beef cows had no detrimental effects on calves' daily weight gain if correct obstetrical techniques were used. Other studies have also suggested that the duration of the second stage of calving could be partly responsible for the negative effects of calving difficulty, and that simple interventions have the potential to reduce the effects of calving difficulty on calves (Lombard et al., 2007; Gundelach et al., 2009).

The aim of this study was to investigate the effects of early assistance given during the second stage of calving to dairy cows that were progressing normally with delivery based on calf presentation and the dilation of the dam's cervix (Villettaz Robichaud, 2016). Specifically, this report focuses on the effect of calving management (assigned and actual calving interventions) on the growth, health, and survival of dairy heifer calves from birth to weaning. The hypothesis was that systematic early assistance at calving, done according to a strict protocol, would have no negative effects on the heifer calves up to weaning.

\section{MATERIALS AND METHODS}

\section{Animal Enrollment and Data Collection}

The institutional animal care committee of the University of Guelph, monitored by the Canadian Council for Animal Care, approved all procedures described in this study. Data collection was conducted between October 2011 and May 2012 on a large commercial dairy farm in western Wisconsin (2,300 lactating Holstein cows). Dry cows from 1 herd (divided in 2 different farms during lactation) were housed together in a 400-stall transition cow facility during the dry period and for the first 15 to $30 \mathrm{~d}$ after calving. Close-up primiparous and multiparous dams were housed in 2 separate freestall pens (90 stalls each) and monitored every 15 to 30 min to detect signs of imminent calving (restlessness, bloody vaginal discharge, visible contractions, appearance of the amniotic sac or limbs of the emerging calf). When imminent calving was detected, the animals were moved to an individual maternity pen $(3.7 \times 3.7 \mathrm{~m})$ bedded with fresh straw.

Primiparous and multiparous cows could enter this calving assistance study at detection of calving if they presented signs of imminent calving, but both front hooves of the calf could not be seen outside the vulva. To be enrolled, the dam must also not have been showing any obvious signs of illness at the time of calving, including lameness, and needed to have sufficient dilation of the cervix to permit an unassisted delivery. Dilation was considered sufficient if the forearm of the principal author (MVR) could entirely enter the birth canal alongside the calf. The calf needed to be a live singleton at the time of vaginal assessment and be in anterior presentation without any malposition for parturition. All vaginal examinations were performed by the same trained person (MVR) to ensure consistency. Once an animal was enrolled in the study (i.e., met all entrance criteria), it was placed in an individual maternity pen and closely observed throughout the calving process.

Dams were randomly assigned to 1 of 2 calving interventions when they entered the study: not assisted (NA) or early assistance (EA). Primiparous and multiparous cows had separate randomization processes, because parity has been found to significantly affect the likelihood of calving difficulties (Lombard et al., 2007). Randomization for each parity group was done in blocks of 8 animals to keep the numbers in each assigned intervention group balanced, and to avoid any potential bias associated with time of enrollment. The EA intervention was defined as cows receiving assistance during calving (pulling of the calf) 15 min after the first sight of the calf's 2 front hooves. The NA intervention group had a cutoff time of $1 \mathrm{~h}$ after first sight of the calf's front hooves, after which late assistance was provided. The 1-h cutoff was chosen to reduce calf losses for the farm, and to be consistent with the farm's standard operating procedure and recent literature (Schuenemann et al., 2011). Among the animals assigned to the EA intervention, some animals calved very rapidly and were not assisted, because expulsion 
of the calf was complete before EA was provided. These animals were classified as "too quick to be assisted." Consequently, we had 4 actual intervention groups: too quick to be assisted (TQ), NA, EA, and late assistance (LA). Because the primary aim of this study was to investigate the effects of assisting all cows at calving, the data were analyzed by assigned interventions (NA and EA) and by actual interventions (TQ, NA, EA, and LA) to allow deeper understanding of the effects of the different calving scenarios.

For vaginal examination and calving assistance, cows' perineal area was thoroughly cleaned using hot water and betadine 7.5\% surgical scrub (Purdue Products LP, Stamford, CT), and disposable obstetrical gloves with lubricant (Lubiseptic; Boehringer Ingelheim Vetmedica Inc., St. Joseph, MO) were used. Assistance during parturition was provided by pulling calves with a stainless steel chain looped around each front leg, proximal and distal to the fetlock joint (2 loops per leg). The majority of cows (91\%) were lying down in their in maternity pen during assistance. Pulling was done using manual force exclusively (as opposed to mechanical force). The same trained person was present during the entire second stage of calving for each cow and provided assistance to all dams that required it, either because of their assigned or actual intervention group. The trained person provided assistance alone or accompanied by farm staff, when needed, to ensure consistency in calving management, assistance technique, and evaluation of calving ease. The number of people pulling to assist a cow and the calving ease were noted at the end of each calving by MVR based on a subjective scale: $1=$ not assisted, 2 = slight assistance (usually 1 person and little force), $3=$ moderate assistance ( 1 or 2 people and moderate force), and $4=$ strong assistance (usually 2 people with strong force). The time between the first appearance of both front hooves and complete expulsion of the calf was recorded as calving duration (min).

After calving, calves were separated from their dams before any suckling occurred. Before colostrum feeding, newborn heifers were weighed $(\mathrm{kg})$ using an electronic scale (Vet Deck; Brecknell, Fairmont, MN) and identified using a unique ear tag, had their navels dipped using a $7 \%$ tincture of iodine solution, and then were placed in a small group pen $(3.6 \times 3.6 \mathrm{~m})$ bedded with fresh straw for the $24 \mathrm{~h}$ following birth. Other information recorded at that time included dam ID, calf ID, birth date, birth time, assigned and actual calving intervention groups, calving ease, sex, birth weight, and dam farm of origin. Dam BCS (5-point scale) and weight were also noted at this time (Ferguson et al., 1994). Heifer calves were then fed 1.5 doses (150 g of $\mathrm{IgG}$ ) of commercially available colostrum replacer
(Land O'Lakes Colostrum Replacer; Land O'Lakes Inc., Arden Hills, MN) using an esophageal tube feeder. The colostrum replacer powder was mixed into $3 \mathrm{~L}$ of warm water before feeding. Heifer calves enrolled in this study were also enrolled in a colostrum study looking at the addition of gut-active carbohydrates to the colostrum replacer to enhance transfer of passive immunity. The results of that study (Villettaz Robichaud et al., 2014) showed no significant effect of this intervention on any of the parameters measured. At $24 \mathrm{~h}$ of age, the heifer calves were moved out of the group pen and placed in freshly bedded individual hutches outdoors, where they were fed $3.8 \mathrm{~L}$ of pasteurized waste milk twice daily, supplemented with a pasteurized milk balancer [Land O'Lakes Pasteurized Milk Balancer (25\% CP, $10 \%$ crude fat), Land O'Lakes Inc. Arden Hills, MN]. Starting at $3 \mathrm{~d}$ of age, heifer calves were offered freechoice water and commercial starter pellet $(20 \% \mathrm{CP})$.

Growth, health, and survival data were collected from birth to weaning at 7 to 8 wk of age. Weaning was done by decreasing the amount of milk offered by $50 \%$ for $3 \mathrm{~d}$ and then by $75 \%$ for $4 \mathrm{~d}$. Calf weight, measured with a girth tape (Holstein calf weight estimation tape; Coburn, Whitewater, WI), was taken at approximately 2 and 7 wk of age. Daily health checks were performed by the farm staff, according their protocols. Calves with signs of diarrhea (yellow or green semi-liquid or liquid manure) or bovine respiratory disease (coughing, heavy breathing, and nasal discharge) were diagnosed, recorded (event, date, and treatment), and treated by farm staff according to the farm's protocol. The death of any animal was recorded by farm staff on a daily basis (date and suspected reason). In the present report, deaths recorded were between $24 \mathrm{~h}$ and $7 \mathrm{wk}$ of age, because the effect of calving intervention on stillbirth (born dead or died within $24 \mathrm{~h}$ of birth) was reported previously (Villettaz Robichaud, 2016). The health data used in this study were based on farm health records.

\section{Statistical Analyses}

The data were analyzed using Stata 11 statistical software (StataCorp LP, College Station, TX). We performed the sample size calculation for the number of animals needed based on the proportion of dams with purulent vaginal discharge, assessed 1 mo after parturition. The calculation assumed that early systematic obstetrical assistance would increase the proportion of animals with purulent vaginal discharge from 17 to $36 \%$ (an outcome to be discussed in a separate manuscript related to the effects of early obstetrical assistance on the dams), which established that a minimum of 125 cows were needed for each assigned intervention. The 
data used in this part of the study were collected on all heifer calves born alive from the dams enrolled in the study.

We generated descriptive statistics to describe the characteristics of the heifer calves and their dams at enrollment. Calving intervention group was forced into each statistical model. To be considered for inclusion in a multivariable model, covariates had to be associated with the outcome with a $P$-value $<0.2$ in univariable analysis. We considered calving ease and the number of people required to pull the heifer calves to be intervening variables between intervention groups (assigned and actual) and the outcomes measured, and did not include them in subsequent models. In the assigned intervention models, we considered calving duration to be an intervening variable, because it was influenced by the intervention assigned. In the actual intervention models, we considered calving duration to be a construction of the actual calving intervention groups, because duration determined the final intervention category; as a result, duration was not included in subsequent models.

We used multivariable linear regression models to analyze the effects of the different calving interventions on the heifer calves' early ADG between birth and $2 \mathrm{wk}$ of age, weight at $7 \mathrm{wk}$, and ADG over $7 \mathrm{wk}$. We used multivariable logistic regression to measure the effects of calving interventions on the likelihood of heifer calves being treated for diarrhea before $7 \mathrm{wk}$, being treated for bovine respiratory disease before $7 \mathrm{wk}$, and dying before the end of weaning at $8 \mathrm{wk}$. The model-building strategy used was a manual backward selection process, where all nonsignificant non-confounder terms were removed from the statistical models, with the exception of calving intervention groups, to create an initial main effects model. Interactions between calving groups and the other main effects were investigated and kept in the models if significant. We could not properly assess the interaction between actual calving interventions and parity because of the absence of primiparous animals in the TQ group and the limited number of multiparous animals in the LA group, so this interaction was not examined. We identified potential confounding variables based on the causal diagram, and retained them in the multivariable models if they were significant or if their removal resulted in a change of $20 \%$ or greater in the coefficient for calving interventions. For linear and logistic models, we used partial F-tests and likelihood ratio tests, respectively, to assess the statistical significance of categorical variables. The significance level for a variable (other than calving intervention group) to be retained in a final model was set at $\alpha=0.05$. The referent calving intervention group category for all models was NA. Heifer calves' birth weight, cows' parity, farm of origin, BCS, width at hip bone, BW, difference in days between expected and actual calving date, and calf/cow weight proportion were tested in the models.

We identified potential collinearity between predictors using Pearson or Spearman correlations, considering 2 variables highly correlated if rho $\geq|0.8|$. In such cases, only the variable with a higher level of interest to the study was used in a final model. The assumption of linearity was assessed visually based on the distribution of residuals against the continuous predictors included in the final models (the linearity assumption was also initially assessed during the univariable analyses). If nonlinear, variables were categorized or modeled as quadratic relationships, if appropriate, based on visual assessment of locally weighted regressions (LOWESS curves).

For linear regression models, we assessed the homoscedasticity of the residuals visually by examining the distribution of the standardized residuals against the predicted values of the outcomes. We assessed the assumption of normality of the residuals visually using normal quantile plots. We identified the outliers and influential observations based on visual assessment of the following diagnostics: standardized residuals, leverage, Cook's distance, and Dfits. For the logistics models, we identified outliers and influential observations based on visual assessment of the following diagnostics: Pearson and deviance residuals, leverage, delta-betas, delta-chisquared, and delta-deviance. The Hosmer-Lemeshow goodness-of-fit test was used to assess the overall fit of the logistic models.

\section{RESULTS}

\section{Animals and Calving Characteristics}

A total of 129 heifer calves were followed from birth through weaning, and they were equally distributed between assigned interventions. Of the heifer calves enrolled, $68 \%$ were born from multiparous dams. We observed a difference in the distribution of dam parity among the actual calving intervention groups: all heifer calves in the TQ group were born from multiparous cows, but $71 \%$ of the heifer calves in the LA group were born from primiparous cows. The primiparous dams' BW averaged [mean \pm standard deviation (SD)] $605 \pm$ $60 \mathrm{~kg}$, with a mean BCS of $3.0 \pm 0.2$ points; the BW of multiparous cows averaged (mean $\pm \mathrm{SD}$ ) $752 \pm 113 \mathrm{~kg}$, with a mean BCS of $3.0 \pm 0.4$ points. The heifer calves' average birth weight was $40.5 \pm 4.5 \mathrm{~kg}$, height at the hip bone was $80 \pm 4 \mathrm{~cm}$, and length was $92 \pm 6 \mathrm{~cm}$, from the midpoint between the ears to the tail.

Detailed information describing calving duration, the number of people pulling, and calving ease by assigned 
and actual calving intervention group is presented in Table 1. Overall, average calving duration from the first appearance of both of the calf's front hooves to complete expulsion was (mean $\pm \mathrm{SD}$; minimum to maximum) 30 $\pm 19 \mathrm{~min}$ and varied from 4 to $80 \mathrm{~min}$ (Table 1 ). Average calving duration was, by definition, longest in the LA group (69 $\pm 6 ; 60$ to $80 \mathrm{~min})$ and shortest in the TQ group (11 $\pm 4 ; 5$ to 18 min) (Table 1$)$. Overall, $75 \%$ of assisted calvings were classified as slight assistance ( 2 on the scale of 1 to 4 ), and only $5 \%$ were considered strong assistance (4 on the same scale). Most assisted heifer calves were pulled by 1 person (Table 1 ).

\section{Effects of Calving Intervention Groups on Growth of Heifer Calves}

We estimated ADG for the heifer calves using girth measuring tape, once early in life, at about (mean \pm SD) $13 \pm 2.9 \mathrm{~d}$ of age, and once at about $7 \mathrm{wk}$, coinciding with the beginning of weaning. Mean ADG from birth to 2 wk of age was $0.73 \pm 0.37 \mathrm{~kg} / \mathrm{d}$, ranging from -0.1 to $2.1 \mathrm{~kg} / \mathrm{d}$. Mean ADG from birth to 7 wk of age was $0.85 \pm 0.18 \mathrm{~kg} / \mathrm{d}$, ranging from 0.28 to $1.23 \mathrm{~kg} / \mathrm{d}$. Heifer calves' weight at weaning averaged $82.6 \pm 10.0 \mathrm{~kg}$, ranging from 46.4 to $105.3 \mathrm{~kg}$, and the average weight gain to weaning was $42.0 \pm 9.3 \mathrm{~kg}$, ranging from 12.7 to $63.6 \mathrm{~kg}$. Neither early ADG (from birth to about 2 wk of age) nor ADG to weaning (from birth to $7 \mathrm{wk}$ ) were significantly influenced by assigned or actual calving intervention (Table 2). Age at early follow-up had a significant association with early ADG, with older calves having a lower ADG at $2 \mathrm{wk}$, maybe indicating that ADG decreased with age during the first $2 \mathrm{wk}$. Average daily gain to $7 \mathrm{wk}$ was significantly lower in heifer calves born from multiparous cows than from primiparous cows (Table 2). We observed a significant interaction between calving intervention group and heifer calves' birth weight on their weight at $7 \mathrm{wk}$ (Table 2); birth weight and weight at $7 \mathrm{wk}$ were positively associated, but the slope and intercept varied across assigned and actual intervention groups (Figure 1). The steepest slopes were in the EA assigned intervention and TQ actual intervention groups.

\section{Effects of Calving Intervention Groups on Health to Weaning}

Health data were collected on 129 heifer calves. A total of $64(50 \%)$ and $38(30 \%)$ of calves in this study (all heifers) required treatment for bovine respiratory disease or diarrhea, respectively, at least once from birth to $7 \mathrm{wk}$ of age. The assessment of the effect of calving on heifers' health was limited by the number of animals enrolled in each intervention group, assigned or actual.

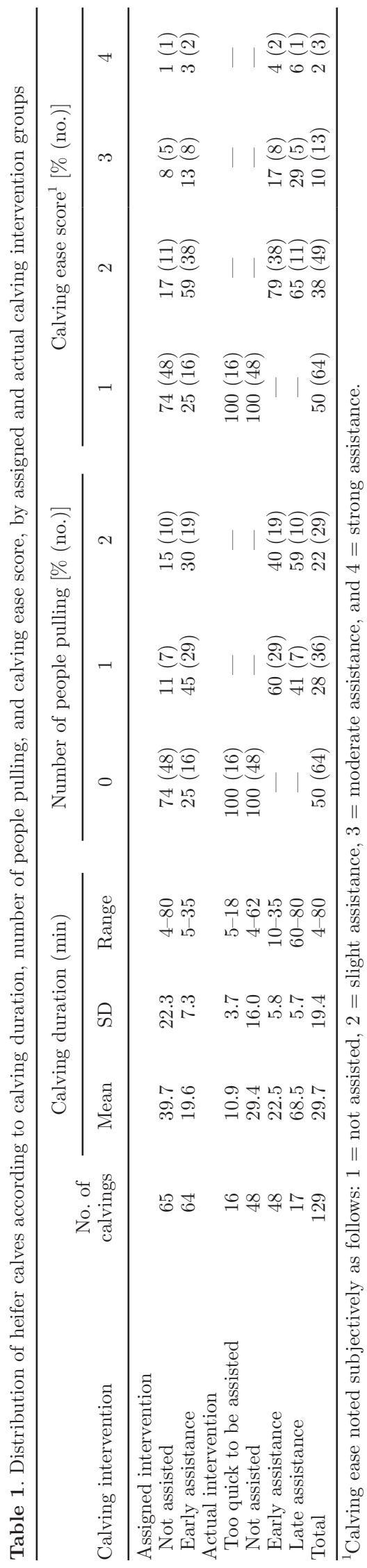

Journal of Dairy Science Vol. 100 No. 1, 2017 
The likelihood of being treated for bovine respiratory disease was not influenced by assigned or actual calving intervention group, but was significantly different depending on the dam's farm of origin (Table 3). The likelihood of heifer calves having diarrhea at any point from birth to weaning was not affected by assigned or actual calving intervention, but was associated with the difference between expected and actual calving date, with the odds of diarrhea significantly increasing for each day the actual date of birth exceeded the expected date (Table 3).

\section{Effects of Calving Intervention Groups on Survival to Weaning}

In total, 14 heifer calves died between $24 \mathrm{~h}$ of age and the beginning of weaning, at 7 wk. The effect of calving intervention on the likelihood of stillbirth has

Table 2. Multivariable linear regression models investigating the effects of assigned and actual calving intervention groups on growth of newborn heifer calves

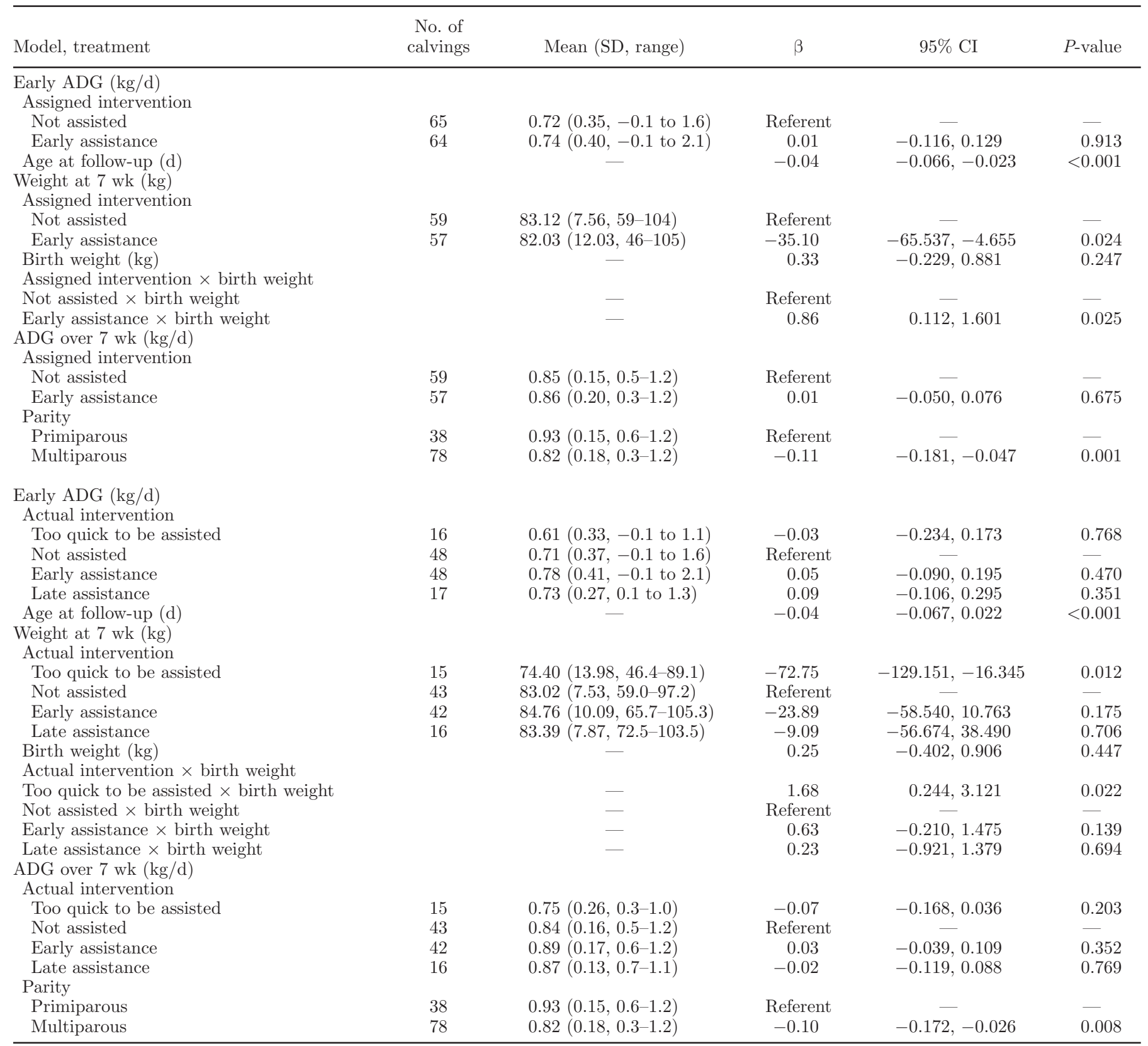


been reported previously (Villettaz Robichaud, 2016). According to assigned intervention, 6 calves died in the NA group (9\%) and 8 in the EA group (13\%). For actual interventions, 2 calves died in the TQ group (13\%), 5 in the NA group (10\%), 6 in the EA group (13\%), and 1 in the LA group (6\%). These deaths were due to euthanasia following leg injuries $(\mathrm{n}=2)$ and death due to bovine respiratory disease $(\mathrm{n}=12)$. No significant differences were found between calving intervention groups, assigned or actual, for the likelihood of heifer calves dying between $24 \mathrm{~h}$ of age and the beginning of weaning at $7 \mathrm{wk}$ (Table 4 ).

\section{DISCUSSION}

Based on the results of the present study, early assistance given during the second stage of calving to dairy cows that showed no signs of calving difficulty did not negatively affect the growth, health, or survival
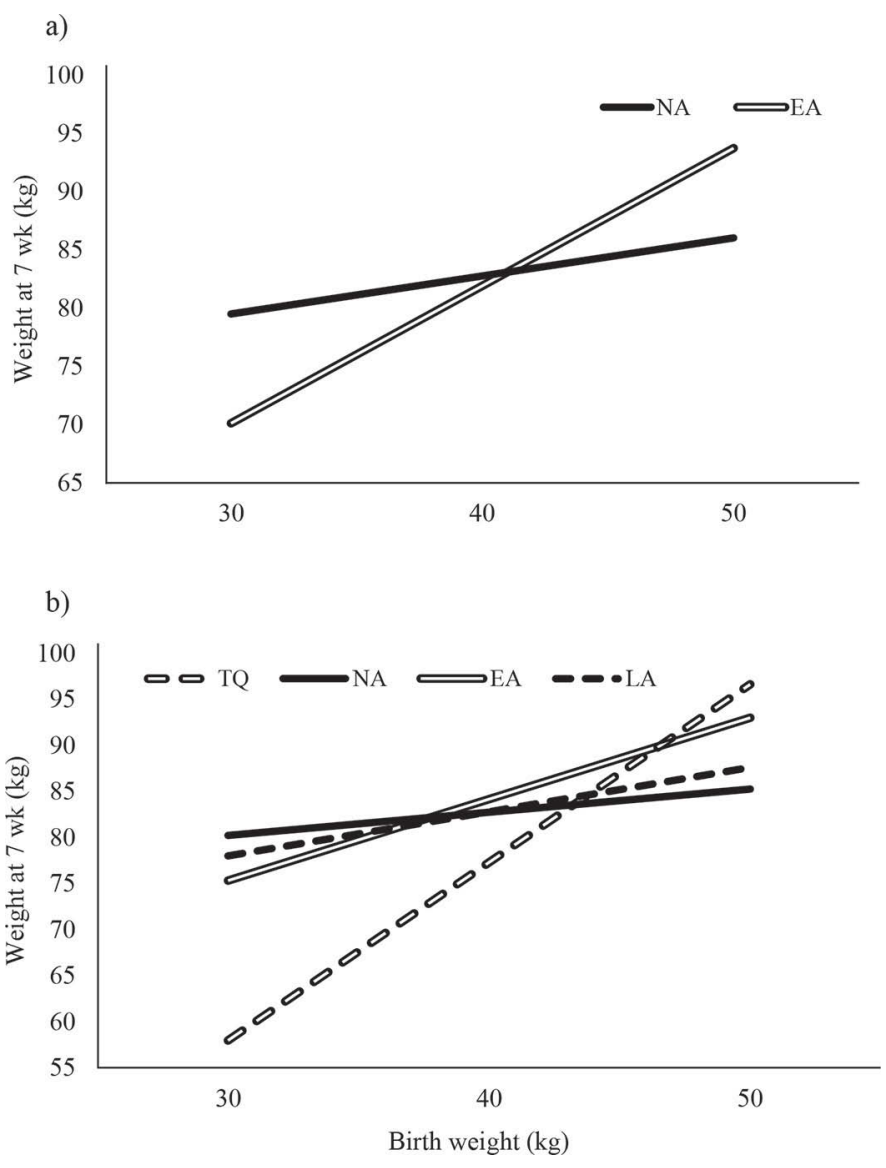

Figure 1. Effect of the interaction between (a) assigned $[\mathrm{NA}=$ not assisted $(\mathrm{n}=59) ; \mathrm{EA}=$ early assistance $(\mathrm{n}=57)]$ and $(\mathrm{b})$ actual [TQ $=$ too quick to be assisted $(\mathrm{n}=15) ; \mathrm{NA}=$ not assisted $(\mathrm{n}=43) ; \mathrm{EA}$ $=$ early assistance $(\mathrm{n}=42) ; \mathrm{LA}=$ late assistance $(\mathrm{n}=16)]$ calving intervention groups and calves' birth weight on BW at $7 \mathrm{wk}$ (total $\mathrm{n}$ $=116)$. of heifer calves between $24 \mathrm{~h}$ of age and weaning. Calving interventions, both assigned and actual, interacted with heifer calves' birth weight to influence their final weight taken at $7 \mathrm{wk}$. The results presented here, along with the ones presented in the first part of the study (evaluating effect of calving interventions on stillbirths and vigor of the newborn), indicate that assisting dairy cows without signs of problems early in the second stage of calving did not negatively affect the health of heifers (Villettaz Robichaud, 2016).

Recently published studies have examined the effect of calving difficulties on the progeny (Heinrichs and Heinrichs, 2011; Barrier et al., 2013). The aim of the present study was to assess the effect of assistance at calving when the animals did not display signs of calving difficulty. We used a block randomization process to ensure equal distribution of primiparous and multiparous dams between the assigned calving interventions, because parity is a well-known risk factor for problems during calving (Lombard et al., 2007; Gevrekci et al., 2011). Similarly, the inclusion criteria of this study included carrying a singleton calf presenting in a forward position without malpresentation, to reduce the odds of dystocia (Gregory et al., 1990; Mee, 2008a). Overall, the characteristics of the heifer calves and their dams enrolled in the current experiment were similar to other reports (Sieber et al., 1989; Johanson and Berger, 2003). The distribution of calving duration, calving ease score, and number of people pulling during calving assistance were consistent with the assigned and actual intervention groups.

The ADG of the heifer calves was measured twice, around 2 wk and again around 7 wk. The mean ADG to weaning of $0.85 \mathrm{~kg} / \mathrm{d}$ calculated in this study was comparable to previously published data (Sivula et al., 1996; Windeyer et al., 2014). For all calving interventions, we observed a significant positive association between birth weight and final weight at $7 \mathrm{wk}$. However, the slope was much steeper and the intercept was closer to the origin for the TQ group. It is unclear biologically why the growth of the calves in this group was so different, but it is important to note that only multiparous cows had calvings that were TQ, and the number of animals in this group was small. Previous studies have examined the effects of calving difficulty on calf growth, but these studies have had contradictory results. Studies similar to this one found no difference in growth between heifer calves born from calvings classified as moderately or highly difficult compared with unassisted ones (Lundborg et al., 2003; Barrier et al., 2012). When looking at the effect of early obstetrical assistance and the induction of parturition in beef cows, Bellows et al. (1988) found that calving intervention did not influence weight gain or final weight 
Table 3. Multivariable logistic regression models investigating the effects of assigned and actual calving intervention groups on the likelihood of calves experiencing pneumonia or diarrhea before weaning ( 7 wk of age)

\begin{tabular}{|c|c|c|c|c|}
\hline Model, treatment & $\%($ no. $/$ total $)$ & Odds ratio & $95 \% \mathrm{CI}$ & $P$-value \\
\hline \multicolumn{5}{|l|}{ Pneumonia event, birth to $7 \mathrm{wk}$} \\
\hline Not assisted & $47.7(31 / 65)$ & Referent & - & - \\
\hline \multicolumn{5}{|l|}{ Dam farm of origin } \\
\hline Dairy 1 & $38.3(23 / 60)$ & Referent & - & - \\
\hline Dairy 2 & $59.4(41 / 69)$ & 2.38 & $1.169,4.839$ & 0.017 \\
\hline \multicolumn{5}{|l|}{ Diarrhea event, birth to $7 \mathrm{wk}$} \\
\hline Not assisted & $32.3(21 / 65)$ & Referent & - & - \\
\hline Early assistance & $26.6(17 / 64)$ & 0.69 & $0.301,1.606$ & 0.395 \\
\hline Days between expected and actual calving date ${ }^{1}$ & & 1.11 & $1.026,1.197$ & 0.009 \\
\hline \multicolumn{5}{|l|}{ Pneumonia event, birth to $7 \mathrm{wk}$} \\
\hline \multicolumn{5}{|l|}{ Actual intervention } \\
\hline Too quick to be assisted & $56.3(9 / 16)$ & 1.33 & $0.411,4.328$ & 0.632 \\
\hline \multicolumn{5}{|l|}{ Dam farm of origin } \\
\hline Dairy 2 & $59.4(41 / 69)$ & 2.34 & $1.130,4.838$ & 0.022 \\
\hline \multicolumn{5}{|l|}{ Diarrhea event, birth to $7 \mathrm{wk}$} \\
\hline \multicolumn{5}{|l|}{ Actual intervention } \\
\hline Too quick to be assisted & $25.0(4 / 16)$ & 0.74 & $0.174,3.159$ & 0.686 \\
\hline Not assisted & $29.2(14 / 48)$ & Referent & & - \\
\hline Early assistance & $27.1(13 / 48)$ & 0.87 & $0.325,2.348$ & 0.788 \\
\hline Late assistance & $41.2(7 / 17)$ & 1.91 & $0.577,6.348$ & 0.289 \\
\hline Days between expected and actual calving date ${ }^{1}$ & - & 1.11 & $1.026,1.120$ & 0.009 \\
\hline
\end{tabular}

${ }^{1}$ Actual calving date minus expected calving date.

in calves at weaning. In contrast, another study found that assisted calvings negatively affected weight gain in newborn dairy calves during the first week of life and ADG to 7 wk of age (Murray, 2014). The same study found that longer calving duration was significantly associated with reduced weight gain in dairy calves over the first 2 wk of life. The method used to determine calf weight at 2 and $7 \mathrm{wk}$ in the present study was girth tape, which has been shown to underestimate weight in calves under 3 mo old, and this might have also reduced our ability to detect a difference between calv- ing interventions (Dingwell et al., 2006). The difference between the findings of the present study and some of the previously published studies might be a result of the EA calving intervention leading to shorter calving duration, and the limited power of this study to assess the effects of LA or longer calvings compared with observational studies.

The assigned and actual calving intervention groups used in this study did not influence the likelihood of heifer calves to be treated for bovine respiratory disease or diarrhea between birth and weaning. Simi-

Table 4. Multivariable logistic regression models investigating the effects of assigned and actual calving intervention groups on the likelihood of calves' death before weaning at $7 \mathrm{wk}$ of age (does not include stillbirth)

\begin{tabular}{lcccc}
\hline Model, treatment & $\%$ (no./total) & Odds ratio & $95 \% \mathrm{CI}$ & $P$-value \\
\hline $\begin{array}{l}\text { Dead at weaning, 24 h to 7 wk } \\
\text { Assigned intervention }\end{array}$ & & & & \\
$\quad$ Not assisted & $9.2(6 / 65)$ & Referent & - & - \\
$\quad$ Early assistance & $12.5(8 / 64)$ & 1.71 & $0.529,5.552$ & 0.369 \\
& & & & \\
Dead at weaning, 24 h to 7 wk & & & & \\
Actual intervention & $12.5(2 / 16)$ & 1.57 & $0.214,7.050$ & 0.623 \\
$\quad$ Too quick to be assisted & $10.4(5 / 48)$ & Referent & - & - \\
$\quad$ Not assisted & $12.5(6 / 48)$ & 1.57 & $0.414,5.965$ & 0.507 \\
$\quad$ Early assistance & $5.9(1 / 17)$ & 0.69 & $0.071,6.620$ & 0.746 \\
$\quad$ Late assistance & & & & \\
\hline
\end{tabular}


larly, Wittum et al. (1994) and Windeyer et al. (2014) found that the odds of neonatal diarrhea or respiratory disease were not influenced by dystocia in beef and dairy calves, respectively. On the contrary, other observational studies have shown that mild and severe dystocia significantly increased the odds of respiratory and digestive problems in dairy heifer calves up to 4 mo of age and also increased non-routine health treatments (Lombard et al., 2007; Barrier et al., 2013).

Finally, in the present study, survival of heifer calves to weaning was not affected by their calving experience. Several observational studies have found that dystocia can significantly increase the odds of a calf dying, but the relationship between the severity of calving difficulty and the odds of the outcome may not increase in a linear pattern (Lombard et al., 2007; Barrier et al., 2012). Statistical power was a potential issue for these outcomes; the distribution of the heifer calves between the assigned and actual intervention groups resulted in a small number of animals in each group, particularly in the TQ and LA groups. However, the difference in the risk of mortality and morbidity appeared quite small, and the sample size required to detect the largest difference observed (i.e., 9.2 vs. $12.5 \%$ in mortality) would have required the recruitment of 3,000 calves (1,500 per group), assuming confidence and power levels of $95 \%$ and $80 \%$, respectively. These results suggest that if the early intervention increased calf morbidity, mortality, or both, the effect would be very small at a producer level, and future studies would need to investigate its effect on a much larger scale.

A potential limitation was the very controlled way that calving interventions were applied to dams. For example, the use of a single highly trained observer for all calvings strengthened the study by limiting the potential bias introduced by variation in observers or obstetricians, but this type of control reduced the generalizability of the results to farms with numerous personnel or less consistent practices. It is likely that most farms employ several people to oversee parturient animals, so by using a single obstetrician we reduced variability that results from "inter-obstetrician" differences in the performance of this intervention. Also, the exclusion from the study of cows presenting known risk factors for calving difficulty may have reduced the apparent benefit of early assistance at calving, because this practice could have resulted in the early detection and correction of various causes of dystocia, including malpresentation. The fact that this experiment was conducted on only 1 farm may also be a limitation. Health assessments were performed daily by farm staff, which may have increased the number of calves diagnosed with diarrhea and bovine respiratory disease, compared with reported averages, because of closer monitoring (USDA, 2010).

Further studies are needed to investigate the specific effects of calving duration, force used during assistance, and duration of assistance during calving. Early assistance at calving, provided to animals without the wellknown risk factors of calving difficulty (multiple births or malpresentation), does not seem to harm calves' growth, health, or survival to weaning. However, to have firmer evidence of these conclusions, a study involving a greater number of animals needs to be conducted and should investigate the outcome of these interventions over the milking life of these animals. Data relative to the effect of calving assistance groups on dams' health, reproduction, and survival have been collected and will be presented in a subsequent manuscript.

\section{CONCLUSIONS}

The use of early assistance as a general calving management practice, given to cows that do not present obvious signs of calving difficulties, does not necessarily affect heifer calves in the early months after birth. The assigned and actual calving interventions interacted significantly with the heifer's birth weight to affect final weight at weaning. However, larger studies are needed to confirm this finding and evaluate the biological mechanism behind this relationship. Further research is needed, ideally with a greater number of animals per calving intervention group, to confirm the results found in the present study and investigate the potential benefits and costs of this management practice on the future health and productivity of heifer calves as mature animals.

\section{ACKNOWLEDGMENTS}

Financial support was provided by Valacta Inc. (Montréal, QC, Canada), the Natural Sciences and Engineering Research Council (Ottawa, ON, Canada), the Ontario Veterinary College (Guelph, ON, Canada) and the Ontario Ministry of Agriculture, Food and Rural Affairs (Guelph, ON, Canada). The authors also thank Ken Leslie (University of Guelph, Guelph, ON, Canada) for his support with the planning of this experiment and the owners (John Vrieze and Brittany Vrieze) and staff (Rolando Juarez, Antonio Oncha, Alejo Gonzalez, Anselmo Ayohua, Nicolas Quechulpa, Juan Quechulpa, Pedro Galvan, and Jacob Flores) at Emerald Dairy II/ Calf-A (Emerald, WI). Without their constant assistance and support, the completion of this study would have been impossible. 


\section{REFERENCES}

Barrier, A. C., C. M. Dwyer, A. I. Macrae, and M. J. Haskell. 2012. Short communication: Survival, growth to weaning, and subsequent fertility of live-born dairy heifers after a difficult birth. J. Dairy Sci. 95:6750-6754.

Barrier, A. C., M. J. Haskell, S. Birch, A. Bagnall, D. J. Bell, J. Dickinson, A. I. Macrae, and C. M. Dwyer. 2013. The impact of dystocia on dairy calf health, welfare, performance and survival. Vet. J. 195:86-90.

Bellows, R. A., R. E. Short, R. B. Staigmiller, and W. L. Milmine. 1988. Effects of induced parturition and early obstetrical assistance in beef cattle. J. Anim. Sci. 66:1073-1080.

Dingwell, R. T., M. M. Wallace, C. J. McLaren, C. F. Leslie, and K. E. Leslie. 2006. An evaluation of two indirect methods of estimating body weight in Holstein calves and heifers. J. Dairy Sci. 89:3992-3998.

Ferguson, J. D., D. T. Galligan, and N. Thomsen. 1994. Principal descriptors of body condition score in Holstein cows. J. Dairy Sci. 77:2695-2703.

Gevrekci, Y., Y. Akbas, and K. Kizilkaya. 2011. Comparison of different models in genetic analysis of dystocia. Kafkas Univ. Vet. Fak. Derg. 17:387-392.

Gregory, K. E., S. E. Echternkamp, G. E. Dickerson, L. V. Cundiff, R. M. Koch, and L. D. Van Vleck. 1990. Twinning in cattle: III. Effects of twinning on dystocia, reproductive traits, calf survival, calf growth and cow productivity. J. Anim. Sci. 68:3133-3144.

Gundelach, Y., K. Essmeyer, M. K. Teltscher, and M. Hoedemaker. 2009. Risk factors for perinatal mortality in dairy cattle: Cow and foetal factors, calving process. Theriogenology 71:901-909.

Heinrichs, A. J., and B. S. Heinrichs. 2011. A prospective study of calf factors affecting first-lactation and lifetime milk production and age of cows when removed from the herd. J. Dairy Sci. 94:336-341.

Johanson, J. M., and P. J. Berger. 2003. Birth weight as a predictor of calving ease and perinatal mortality in Holstein cattle. J. Dairy Sci. 86:3745-3755.

Lombard, J. E., F. B. Garry, S. M. Tomlinson, and L. P. Garber. 2007. Impacts of dystocia on health and survival of dairy calves. J. Dairy Sci. 90:1751-1760.

Lundborg, G. K., P. A. Oltenacu, D. O. Maizon, E. C. Svensson, and P. G. A. Liberg. 2003. Dam-related effects on heart girth at birth, morbidity and growth rate from birth to 90 days of age in Swedish dairy calves. Prev. Vet. Med. 60:175-190.
Mee, J. F. 2008a. Prevalence and risk factors for dystocia in dairy cattle: A review. Vet. J. 176:93-101.

Mee, J. F. 2008b. Newborn dairy calf management. Vet. Clin. North Am. Food Anim. Pract. 24:1-17.

Murray, C. 2014. Characteristics, risk factors and management programs for vitality of newborn dairy calves. $\mathrm{PhD}$ Thesis. University of Guelph, Guelph, ON, Canada.

Schuenemann, G. M., I. Nieto, S. Bas, K. N. Galvao, and J. Workman. 2011. Assessment of calving progress and reference times for obstetric intervention during dystocia in Holstein dairy cows. J. Dairy Sci. 94:5494-5501.

Sieber, M., A. E. Freeman, and D. H. Kelley. 1989. Effects of body measurements and weight on calf size and calving difficulty of Holsteins. J. Dairy Sci. 72:2402-2410.

Sivula, N. J., T. R. Ames, and W. E. Marsh. 1996. Management practices and risk factors for morbidity and mortality in Minnesota dairy heifer calves. Prev. Vet. Med. 27:173-182.

USDA. 2010. Dairy 2007. Heifer calf health and management practices on U.S. dairy operations, 2007. No. N550.0110. Centers for Epidemiology and Animal Health, USDA-APHIS-VS, Fort Collins, CO.

Villettaz Robichaud, M. 2016. Prevalence and effects of management practices around calving on the health, behaviour, and productivity of Holstein dairy calves. PhD Thesis. University of Guelph, Guelph, ON, Canada.

Villettaz Robichaud, M., A. M. de Passillé, D. L. Pearl, S. J. LeBlanc, S. M. Godden, D. Pellerin, E. Vasseur, J. Rushen, and D. B. Haley. 2016. Calving management practices on Canadian dairy farms: Prevalence of practices. J. Dairy Sci. 99:2391-2404.

Villettaz Robichaud, M., S. M. Godden, D. H. Haines, D. B. Haley, and D. L. Pearl. 2014. Addition of gut active carbohydrates to colostrum replacer does not improve passive transfer of immunoglobulin G in Holstein dairy calves. J. Dairy Sci. 97:5700-5708.

Windeyer, M. C., K. E. Leslie, S. M. Godden, D. C. Hodgins, K. D Lissemore, and S. J. LeBlanc. 2014. Factors associated with morbidity, mortality, and growth of dairy heifer calves up to 3 months of age. Prev. Vet. Med. 113:231-240.

Wittum, T. E., M. D. Salman, M. E. King, R. G. Mortimer, K. G. Odde, and D. L. Morris. 1994. Individual animal and maternal risk factors for morbidity and mortality of neonatal beef calves in Colorado, USA. Prev. Vet. Med. 19:1-13. 